\title{
EVALUATION OF AGRICULTURE SOIL QUALITY BY TREATED WASTEWATER REUSE IN ARID REGIONS: CASE STUDY IN SISTAN AND BALUCHESTAN PROVINCE, IRAN
}

\author{
G. BADALIANS GHOLIKANDI ${ }^{1} \&$ M. KHOSRAVI ${ }^{2}$ \\ ${ }^{1}$ Power and Water University of Technology (PWUT), Water Research Institute (WRI), Tehran, Iran. \\ ${ }^{2}$ Water Research Institute (WRI), Water and Wastewater Research Center (WWRC), Tehran, Iran.
}

\begin{abstract}
In this paper, the reuse of reclaimed wastewater for irrigation of agricultural land and its effect on soil quality has been investigated in an arid region of Iran. For this purpose, two pilots of $2,000 \mathrm{~m}^{2}$ area with a variety of plants were selected near the effluent discharge of a wastewater treatment plant (WWTP) in Zahedan and Zabol cities in Sistan and Baluchestan Province. The wastewater treatment systems at Zahedan and Zabol were activated sludge (extended aeration) and aerated lagoons, respectively. In this study, 14 types of native plants were selected and seeded in 18 rows and treated wastewater was reused for irrigation of the pilots. The samples were taken from the effluent of the WWTP and analyzed from the viewpoint of quality. Results showed that indicators of sodium adsorption ratio (SAR), sodium percentage (Na\%) and electrical conductivity (EC) were higher than standard levels set by the Food and Agricultural Organization (FAO). Other parameters such as total dissolved solids, $\mathrm{pH}$, biochemical oxygen demand, chemical oxygen demand and turbidity were in the standard range. To assess soil quality, sampling was conducted in two stages that included irrigation with fresh water and irrigation with treated wastewater. Soil analysis showed that soil structure is loamy with high salinity and alkalinity. Soil quality in the 12 month period after irrigation was studied and investigated; although the treated wastewater quality in some cases was beyond the FAO irrigation standard range, there was no adverse effect on the soil quality, e.g. EC, SAR and exchangeable sodium percentage (ESP). In the Zahedan pilot, the values of soil EC, SAR and ESP decreased to $82 \%, 75 \%$ and $66 \%$ after irrigation with treated wastewater. The soil quality of the Zabol pilot decreased after 6 months, but on continuation of the irrigation for 12 months, the values for EC, SAR and ESP decreased to $49 \%, 25 \%$ and $24 \%$, respectively. The results show that the reuse of reclaimed wastewater is an economical and beneficial method for irrigation of agriculture land in the arid regions of Iran. Finally, an artificial neural network model, which adopts a back propagation algorithm with momentum and adaptive learning rate, was applied. The effect of each parameter on the performance of the Zahedan pilot was compared, using the partitioning connection weights method. The result is $\mathrm{EC}_{\text {effluent }}>\mathrm{EC}_{\text {soil }}>$ $\mathrm{SAR}_{\text {soil }}>\mathrm{BOD}_{5}>\mathrm{ESP}_{\text {soil }}>\mathrm{SAR}_{\text {effluent }}$. In addition, many strategies were proposed to optimize the working conditions of the system.

Keywords: artificial neural network, arid regions, irrigation, reuse of wastewater, soil quality.
\end{abstract}

\section{INTRODUCTION}

About 80 countries and regions, representing $40 \%$ of the world's population, are experiencing water stress, and about 30 of these countries are suffering from water scarcity during a large part of the year [1]. During the last four decades, the number of countries experiencing water scarcity, most of which are developing countries, has increased. This number is expected to reach 34 by the year 2025 and Iran is one of them [2].

Collection and treatment of wastewater as well as subsequent reclamation and reuse in one or more ways has become a feasible option these days. Reuse of reclaimed wastewater (RRW) is an opportunity to shorten the hydrological cycle until the water is used again [3, 4]. RRW in agriculture has been shown as an important management issue for sustainable management of limited freshwater resources. This practice is important because of the potential economic and environmental benefits [5]. On average, $60 \%$ of wastewater in the United States is reused [6, 7]. About 400 million cubic meters of 
wastewater is treated in the state of California of which about 300 million cubic meters is used in agricultural activities [8]. More than 13 million cubic meters of treated wastewater is reused in agricultural activities in Japan [9]. In Mediterranean countries, due to population increase and periodic drought municipal and agriculture authorities are considering the RRW. In these countries, 70-80\% of water demand arises from agricultural and landscape irrigation. As a result, and because of local water shortages, irrigation with domestic wastewater is a common practice, even without appropriate treatment or disinfection. In the EU, the recent acute droughts and dry periods are pushing wastewater reuse to the top of the agenda [10].

In Spain [11], there were approximately 140 reuse activities that rose from $346 \mathrm{hm}^{3} /$ year (cubic hectometer per year) in 2001 to $408 \mathrm{hm}^{3} /$ year in 2004 [12]. In Cyprus, the 25 million cubic meters of wastewater generated per year is planned to be collected and used for irrigation after tertiary treatment [13]. In the Middle East, considering the water crises, investigations on RRW have begun. Pioneer countries are Morocco, Jordan, Pakistan, Oman and Saudi Arabia [14].

In Iran, the renewable water per capita was $1,830 \mathrm{~m}^{3} /$ year in 1996 , but will be only $1,200 \mathrm{~m}^{3} /$ year in 2020 [15]. The average of annual precipitation in Iran is less than $250 \mathrm{~mm}$ (one-third of the world's precipitation) and water resources per capita decreased from 7,000 $\mathrm{m}^{3}$ in 1956 to $4,300 \mathrm{~m}^{3}$ in 2001 and are forecast to be $1,300 \mathrm{~m}^{3}$ in 2020 . Thus, Iran might suffer from a lack of water in the future. In some regions water scarcity is a problem even now. The solution to this problem is the recycling and reuse of domestic wastewater as a worthy option. The volume of domestic wastewater in Iran is more than 18 billion cubic meters and is expected to reach 40 billion cubic meters. The maximum ability of rivers to drain wastewater is six billion cubic meters, which is much less than the amount of wastewater produced in Iran. Most parts of Iran, especially the south, are arid and characterized by low annual precipitation, so RRW for agriculture is one of the strategies adopted for increasing water supply. Because of the shortage of water in different parts of Iran, treated or untreated wastewaters are becoming an increasingly important source of irrigation water. The demands of the growing urban communities for both food and water require the agricultural sector to not only increase food production but to also reduce its use of natural water resources [16].

Wastewater reuse projects have been of special interest in Iran because of their potential in saving significant amount of water in this water stressed country. A study to determine the potential of wastewater reuse in Ardebil (northwest of Iran) was carried out and it was found that the effluents from the Ardebil wastewater treatment plant (WWTP) would not pose any restrictions for its reuse in agriculture [17]. In another study carried out by Salehi Arjmand et al. [18] the emphasis was on determining the concentrations of chemical constituents present in the Arak district WWTP effluent, and thus the amounts of many heavy metals were measured. They finally reported that no chemical contamination was present, thus concluding that many crops could be irrigated using this effluent. However, their recommendation was meant specifically for the use of the effluent for irrigation of non-edible crops. The study of wastewater reuse opportunities in the city of Yazd was the subject of a research conducted by Amjad et al. [19]. The WWTP in the province Yazd comprises a series of stabilization ponds and the use of the final effluent in agricultural irrigation was considered to be a safe action. In Shiraz (one of the big cities in Iran), industrial and domestic wastewater from more than 80 units are dumped into the Khoshk River and in the southeast of Shiraz in different seasons this wastewater is used for agricultural purposes [20].

A back propagation (BP) neural network, as a universal approximation, has strong stability. It can approach any non-linear system dynamically, and the network weights can be altered by the input of new training data, to achieve dynamic adjustment of the model. Therefore, it is suitable to establish models for highly non-linear and strong coupling systems. Many studies have shown that the understanding among people about the use of neural networks in the field of wastewater treatment was still 
at a low level [21]. Therefore, there is a good prospect and profound significance in using neural networks to optimize control parameters of the reactor and propose strategies for the stable performance of the reactor.

In this study, one of the arid provinces of Iran, Sistan and Baluchestan Province, which has been facing water deficit and environmental crisis for a long time, is selected as a case study for the evaluation of RRW in agricultural irrigation.

The Sistan and Baluchestan Province is located in the southeast of Iran between $25^{\circ} 3^{\prime}$ and $31^{\circ} 28^{\prime} \mathrm{N}$ latitude and $58^{\circ} 47^{\prime}$ and $63^{\circ} 19^{\prime} \mathrm{E}$ longitude. The province covers an area of about $191,000 \mathrm{~km}^{2}$ of which Sistan Region forms 5\% and the remaining 95\% is Baluchestan. The area of this province is about oneninth of the country's area. Considering that the study was conducted in a special region, Sistan and Baluchestan Province, and that the Zahedan and Zabol regions have been selected for pilot studies, the investigation and recognition of the natural characteristics of the these regions will have considerable importance. The limitation in terms of water resources and the high cost to obtain good quality water for agriculture makes it necessary to consider RRW for the irrigation of plants that can cope with the arid climate in this province. Several mechanisms have been hypothesized to cause changes in soil properties when an effluent is used for irrigation. The suspended solids in the effluent can block the water-conducting pores in the soil and, in addition, effluent irrigation can change the soil's chemical and biological properties, such as exchangeable sodium percentage (ESP), salinity, organic matter content and quality, and micro-organism activity, all of which can affect the soil-structure stability and soil-pores architecture. Organic constituents applied with the effluent can also increase the soil's water repellency [16].

This paper focuses on the RRW for irrigation of agricultural plants on a pilot scale and the evaluation of the physical and chemical properties of soil; the effect of each parameter on the performance of the pilot is compared owing to irrigation with treated wastewater in an arid region in Iran for first time.

\section{MATERIALS AND METHODS}

\subsection{Geographical and climatic conditions of the region}

The Sistan and Baluchestan Province is located between Pakistan on the east and the Gulf of Oman in the south; the Loot Desert in the east and northeastern part causes wind flows. The geological formation of the province includes mainly sedimentary and igneous stones from the third era and alluvial deposits from the fourth era. One of the major problems in the province is the improper soil conditions and its relatively low quality. The majority of soils in the province are alluvial soils with poor organic content. The main source of these soils is alluvium and other settlements moved by the wind, all belonging to the fourth era. Marn, gypsum, silt, sand and salt are the main components forming the soils in the province. The alluvial soils of the province are comprised of fine particles and owe their life to the Hirmand and Hamoon Rivers. Soil erosion is relatively high in this province and is caused by seasonal floods and the heavy winds in the region [22]. Due to special geographic characteristics and desert conditions, the region does not have a rich vegetation. The existing forest and other plant species mainly include Iranian screw bean, tamarisk, Pakistan screw bean, Accacia bambulah, marsh arrow grass, reed, wild cotton and cape tree [23]. As the province is located in a region with an arid and semi-arid climate, the annual precipitation is very low and, due to its long distance from regions of humidity and rainfall in the west, it does not have rich surface and ground water resources [24]. The geographical and climatic conditions and the location of the pilots in Zahedan and Zabol cities are shown in Fig. 1.

Considering the isothermal map of the province, the maximum temperatures in the Zahedan and Zabol stations are $42.6^{\circ} \mathrm{C}$ and $49^{\circ} \mathrm{C}$, respectively. The minimum annual temperature in these cities is 


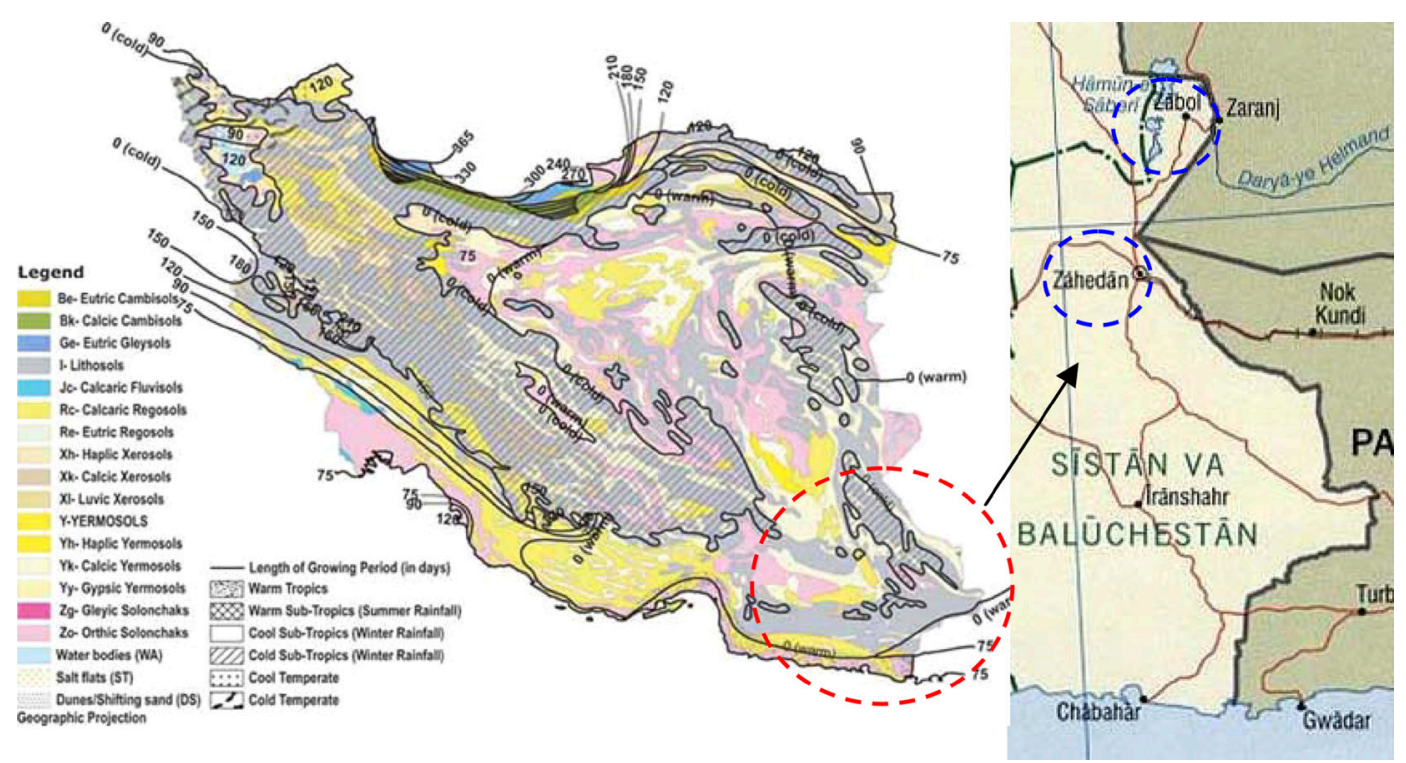

Figure 1: Geographical and climatic conditions and location of pilots.

about $-10^{\circ} \mathrm{C}$ and glacial days in this area are in winter that has no effect on agricultural products. Regional winds in the province are focused on the 120-day Sistan winds. From the point of view of the blowing limitation and durability, these winds are unique and blow from the northeast mountains of Iran to the southeast region of the country from early May to late September. The wind is very humid and fresh in the south Alborz hills and, after passing through the Kawir and Loot Deserts, becomes hot and arid and, especially in the Sistan region, causes serious damage to the vegetation by drastic soil erosion. Wind blast causes evaporation in lakes and plants and therefore increases the water requirement for agriculture. In Sistan and Baluchestan Province continuous winds and the fine size soil result in dusty hurricanes which cause soil erosion and, consequently, destroy the valuable resources of the province. The number of dusty days in Zahedan and Zabol are 180 and 70 days, respectively. The 120-day winds are also known to cause physical injury, including $28 \%$ of blindness cases in the Kratit region [23]. Annual precipitation and its changes have a direct effect on agriculture in arid regions such as Zahedan and Zabol. The annual precipitation of the province varies from a minimum of $65 \mathrm{~mm}$ in Zabol to a maximum of $165 \mathrm{~mm}$ in Khash Station; considering the average annual precipitation of the country (about $260 \mathrm{~mm}$ ), almost all stations have an annual precipitation less than the average for the country. February and March are the most humid months of the year $(20-25 \mathrm{~mm})$ and June is the most arid month $(0-5 \mathrm{~mm})$. The annual radiation in all synoptic stations of the province is more than $3,000 \mathrm{~h}$, whereas the same parameter in northern cities of the country is $2,100 \mathrm{~h}$ [24].

Because of the small amount of precipitation and considerable evaporation in this province, RRW is the most important method for irrigation of agricultural lands [25].

\subsection{Pilot construction}

Considering the results of the investigation and basic information, the area for the pilots and plant species were selected and after preparation of the landscape, the seedlings were planted. The area of each pilot was 2,000 $\mathrm{m}^{2}$ with different dimensions that was established near WWTP sites in Zahedan and Zabol in Sistan and Baluchestan Province. 
Soil analysis showed that soil structure is loamy with high salinity and alkalinity. Generally, the soil used for landscapes and green spaces should be a light soil with enough depth and suitable electrical conductivity (EC) and $\mathrm{pH}$; otherwise soil amendment, fertilization and even soil replacement would be required. In this study, 14 types of native plants were selected and seeded in 18 rows and treated wastewater was reused for irrigation of the pilots. The pictures and schematic plans of the pilots are outlined in Figs 2-4.

For irrigation of the pilots with treated wastewater, a 110-mm diameter pipe was used and it was joined with a 0.75 inch pipe for the distribution of wastewater in the pilot surface. The wastewater treatment system at the Zahedan plant is activated sludge (extended aeration) built in a residential complex, east of Zahedan. The wastewater treatment system in Zabol City comprises aerated lagoons (first stage) with settlement facultative ponds (second stage) and maturation ponds (third stage). Effluent characteristics of the wastewater from Zahedan and Zabol WWTP and its comparison with the Iranian Environmental Protection Organization (IREPO) and Food \& Agriculture Organization (FAO) standards are shown in Table 1 [25].

\subsection{The foundation of the BP neural network model}

The BP neural network model was established using the Matlab platform. The mathematical models were established by big functions of the Matlab Neural Network toolbox.
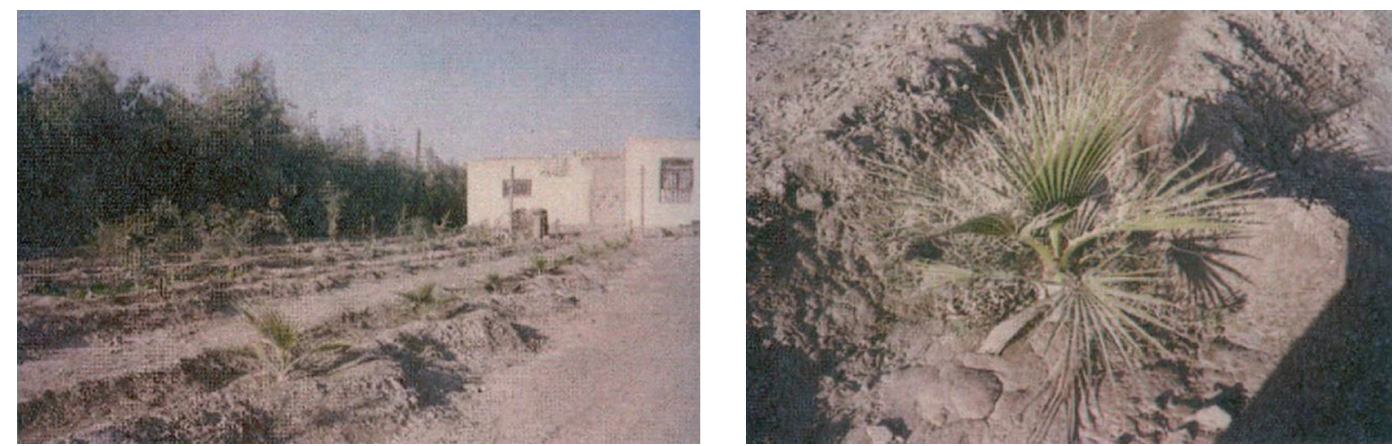

Figure 2: Zabol pilot (3 months after planting) [16].
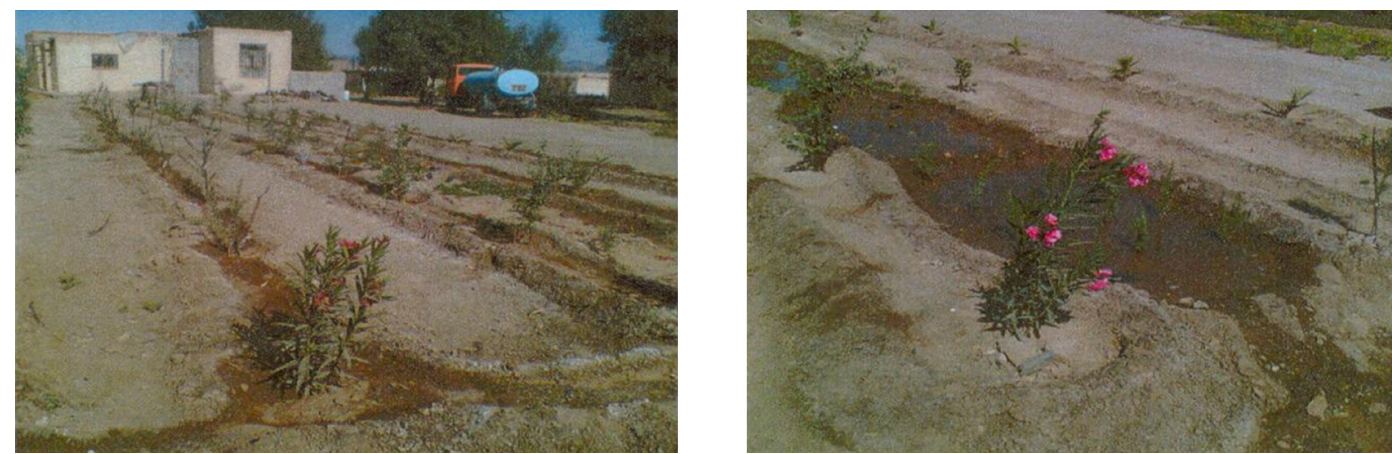

Figure 3: Zahedan pilot (3 months after planting) [16]. 


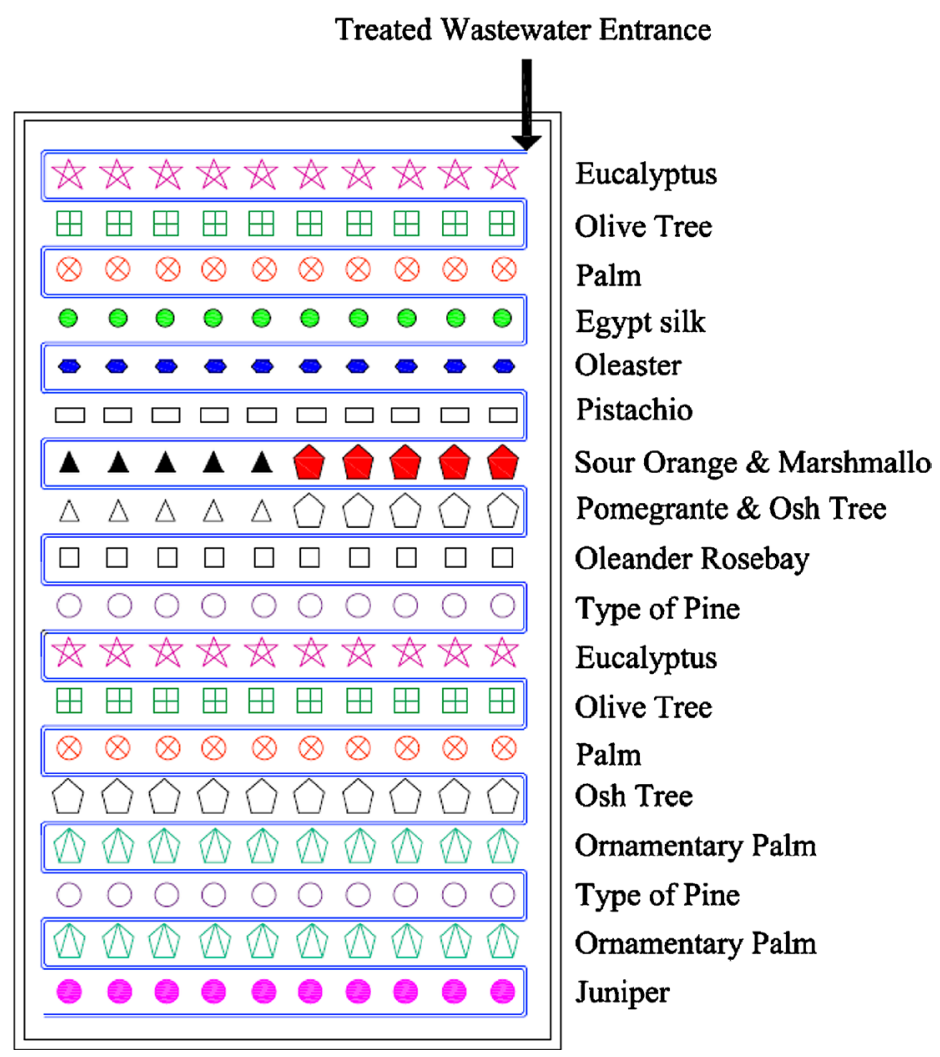

Figure 4: Schematic plan of Zahedan and Zabol pilots [16].

2.3.1 The structure of the BP neural network

The input layer of the network included six parameters: influent chemical oxygen demand (COD), biochemical oxygen demand $\left(\mathrm{BOD}_{5}\right), \mathrm{EC}$, sodium adsorption ratio (SAR), $\mathrm{pH}$ and alkalinity. These parameters are the operational characteristics of the reactor; they play a key control role and are easy to quantify. They had the peculiarities of generality and were used in the neural network. The hidden layer adopted a monolayer structure and included three neurons to ensure that the uncertain weights occupied half of the training sample. The output parameters of Stage 1 were $\mathrm{BOD}_{5}$, EC and SAR. In the next stage, the output parameters of Stage 1 and soil characteristics before pilot construction, such as ESP, SAR, EC, were used as the input layer for the network soil quality forecasting. The output parameters of Stage 2 were $\mathrm{SAR}_{\text {soil }}, \mathrm{EC}_{\text {soil }}$ and $\mathrm{ESP}_{\text {soil }}$. The topological architecture of the $\mathrm{BP}$ neural network is illustrated in Fig. 5.

\subsubsection{The origin of training and forecasting data}

The training data came from the data of the pilot operation (Zahedan) running steadily after 365 days. About 45 representative groups of data were selected for training and 14 groups (Table 2) for forecasting.

The hidden layer and output layer adopted tansig and purelin as the activation functions, respectively. Traingdx, one of the adaptive training functions with momentum was utilized by the network 
Table 1: Comparison of Zahedan and Zabol wastewater treatment plant (WWTP) effluents with standards $[7,8]$.

\begin{tabular}{|c|c|c|c|c|c|c|}
\hline \multirow[b]{2}{*}{ Parameter } & \multirow[b]{2}{*}{ Unit } & \multicolumn{2}{|c|}{ WWTP effluent } & \multirow{2}{*}{$\begin{array}{l}\text { IREPO } \\
\text { standard }\end{array}$} & \multirow{2}{*}{$\begin{array}{c}\text { FAO } \\
\text { standard }\end{array}$} & \multirow[b]{2}{*}{ Standard range } \\
\hline & & Zahedan & Zabol & & & \\
\hline $\mathrm{pH}$ & - & 7.1 & 7.2 & $6.0-8.5$ & $6.8-8.4$ & $6.0-8.5$ \\
\hline & $\mu \mathrm{s} / \mathrm{cm}$ & 5,440 & 4,250 & - & $2,500-3,000$ & 250-750: Good quality \\
\hline EC & & & & & & $\begin{array}{l}\text { 750-2,000: Acceptable } \\
\text { 2,000-3,000: Questionable }\end{array}$ \\
\hline TDS & $\mathrm{mg} / \mathrm{L}$ & 746 & 736 & - & $<2,000$ & $\begin{array}{l}<450: \text { Suitable quality } \\
\text { 450-2,000: Intermediate } \\
>2,000: \text { Severe limitation }\end{array}$ \\
\hline TSS & $\mathrm{mg} / \mathrm{L}$ & 76 & 95 & $<100$ & - & Maximum acceptable: 100 \\
\hline $\mathrm{BOD}_{5}$ & $\mathrm{mg} / \mathrm{L}$ & 98 & 63 & $<100$ & - & Maximum acceptable: 100 \\
\hline $\mathrm{COD}$ & $\mathrm{mg} / \mathrm{L}$ & 196 & 146 & $<200$ & - & Maximum acceptable: 200 \\
\hline $\mathrm{Ca}^{2+}$ & $\mathrm{mg} / \mathrm{L}$ & 50 & 45 & - & $<400$ & - \\
\hline $\mathrm{Mg}^{2+}$ & $\mathrm{mg} / \mathrm{L}$ & 15 & 25 & $<100$ & $<61$ & Maximum acceptable: 100 \\
\hline $\mathrm{Na}^{+}$ & $\mathrm{mg} / \mathrm{L}$ & 570 & 565 & - & $<460$ & Measured with SAR and $\mathrm{Na} \%$ \\
\hline $\mathrm{K}^{+}$ & $\mathrm{mg} / \mathrm{L}$ & 33 & 50 & - & - & - \\
\hline $\mathrm{Cl}^{-}$ & $\mathrm{mg} / \mathrm{L}$ & 570 & 550 & $<600$ & $<350$ & Maximum acceptable: 600 \\
\hline $\mathrm{SO}_{4}^{2-}$ & $\mathrm{mg} / \mathrm{L}$ & 310 & 250 & $<500$ & - & Maximum acceptable: 500 \\
\hline $\mathrm{HCO}_{3}$ & $\mathrm{mg} / \mathrm{L}$ & 150 & 320 & - & $<610$ & Measured with RSC index \\
\hline SAR & - & 18.1 & 16.7 & - & $<9$ & $\begin{array}{l}\text { <8: Suitable } \\
\text { 8-15: Acceptable } \\
>18: \text { Unsuitable }\end{array}$ \\
\hline Turbidity & NTU & 55 & 36 & $<75$ & - & Maximum acceptable: 75 \\
\hline Total alkalinity & $\mathrm{mg} / \mathrm{L} \mathrm{CaCO}_{3}$ & 93 & 108 & - & - & - \\
\hline Total coliform & MPN/100 mL & 206 & 140 & $<1,000$ & - & - \\
\hline
\end{tabular}

BOD, biochemical oxygen demand; COD, chemical oxygen demand; EC, electrical conductivity; SAR, sodium adsorption ration; TDS, total dissolved solids; TSS, total suspended solids.

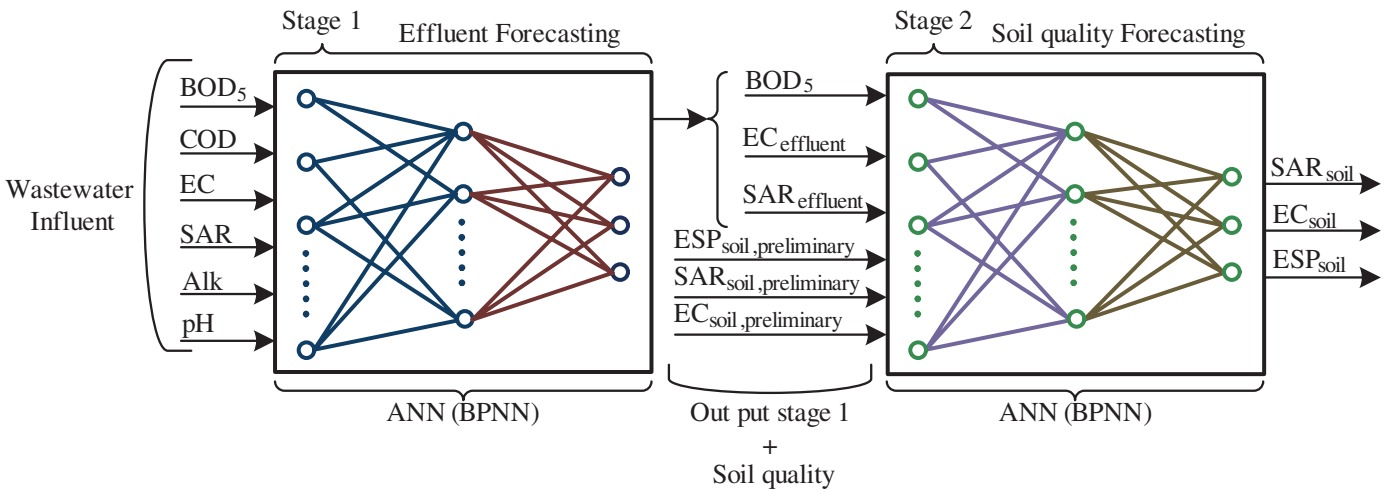

Figure 5: Topological architecture of the back propagation neural network model. 


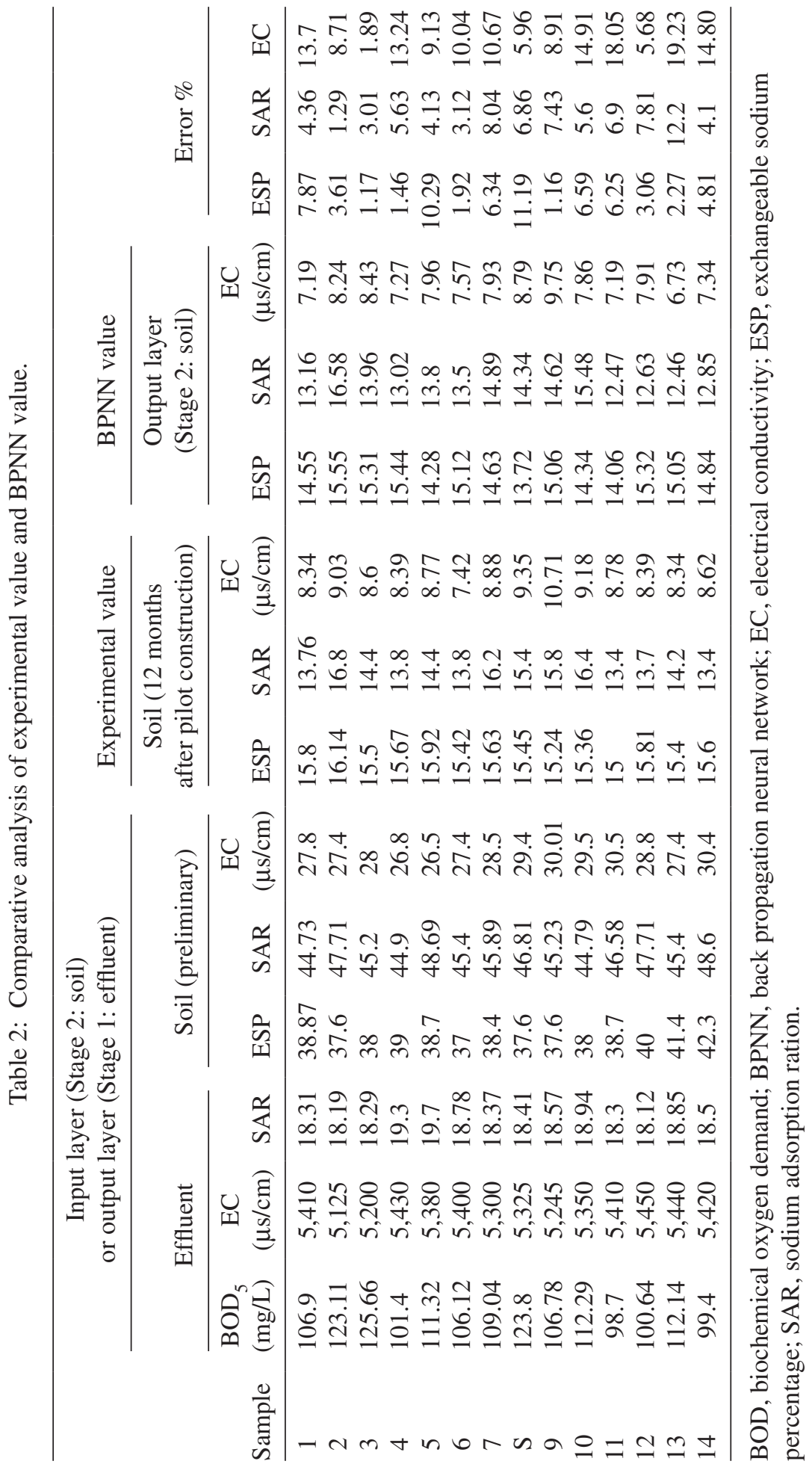


training. This algorithm, based on the classical BP algorithm, was able to modulate learning rate automatically and incidental momentum, which avoided local minimum and accelerated the convergence rate greatly.

Reorganization of the main factor and multi-factor simulation for the prototype experiments means to take advantage of the BP neural network to set up the mapping relationships between all relative factors and results, which reflects the direct and indirect influences of all the factors on the reactor's performance [26]. The weights of neural units in the network can not only store information but also guide the direction of the information. According to information flow theory, the value of the weights determines the direction in which information flows. As a result, the value of the weights shows the contributions of the input factors to the final output.

The partitioning connection weights method is used to separate the weights of the hidden layer and output layer and connect them with the input layer directly [27]. Then, the relative importance (RI) of all the input factors was calculated, and the importance of the input factors was quantitatively analyzed. The algorithm consisted of eqns (1) and (2).

$$
\begin{gathered}
\mathrm{Q}_{\mathrm{ih}}=\frac{\left|\mathrm{W}_{\mathrm{ih}}\right|}{\sum_{\mathrm{i}=1}^{\mathrm{ni}}\left|\mathrm{W}_{\mathrm{ih}}\right|} \\
\mathrm{RI}(\%)_{\mathrm{i}}=\frac{\sum_{\mathrm{h}=1}^{\mathrm{nh}} \mathrm{Q}_{\mathrm{ih}}}{\sum_{\mathrm{h}=1}^{\mathrm{nh}} \sum_{\mathrm{i}=1}^{\mathrm{ni}} \mathrm{Q}_{\mathrm{ih}}} \times 100
\end{gathered}
$$

where $\mathrm{W}_{\mathrm{ih}}$ is the weight between the input layer and hidden layer and $\mathrm{nh}$ and ni are the numbers of neural units in the hidden layer and input layer, respectively.

\section{RESULTS}

The results of our periodical investigations show the optimum growth and development of most of the planted species. Of the 200 plants, only the growth of some pistachio plants was inappropriate; however, the phenomenon was observed only in four plants out of the total of 20 pistachio plants. Pistachio is a plant that needs little water and in the case of continuous irrigation the plant will be damaged as a result of root rot. Some other factors also had an influence in this regard, including the failure to observe appropriate principles of planting practice and root damage at the time of transplanting. These problems were solved by renewal transplanting and change of the irrigation regime. Irrigation periods were divided into fresh water irrigation and irrigation with treated wastewater. Irrigation with effluents can change the chemical properties of the irrigated soils. The quality of the soils during both periods of irrigation was determined. These pilots had been irrigated with secondary effluent. Prior to pilot establishment, the qualitative structure and classification of the soil was examined by drilling holes at depths of $0-30 \mathrm{~cm}, 30-60 \mathrm{~cm}$ and also $1.5-2 \mathrm{~m}$. The chemical and physical characteristics of the soil were studied before and after irrigation and are summarized in Figs 6-11.

\subsection{Principal factor identify}

After 5,540 times of training, the target error was reduced to 0.01 and then training was stopped. Fourteen groups of typical data different from training sets were used to predict models. The results of regression analysis showed that the correlation coefficient between the predicted value and experimental value was 0.99 , which indicated that the simulation results were in good agreement 


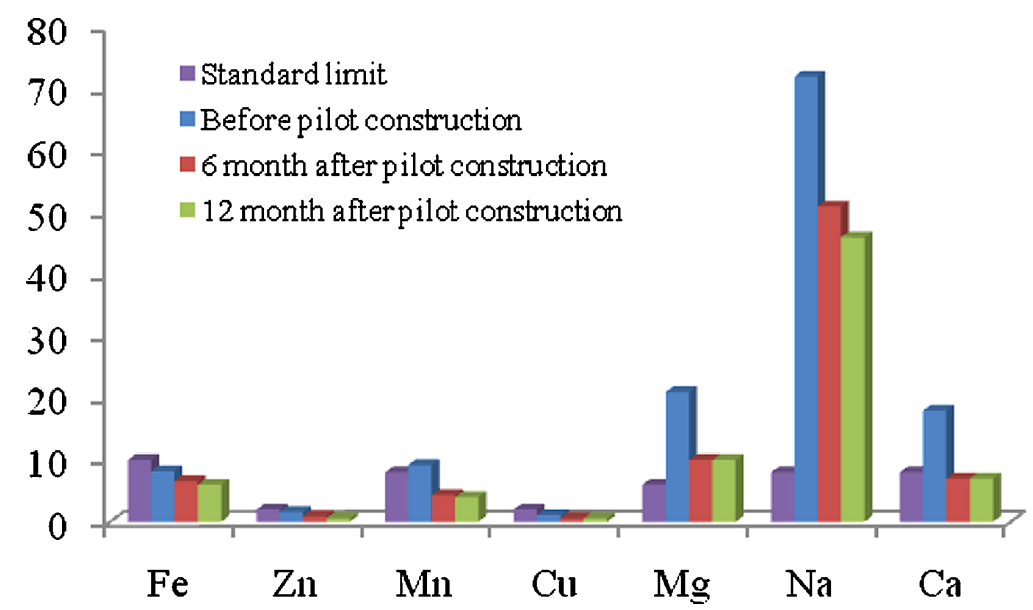

Figure 6: Chemical properties of the soil before and after the establishment of the Zabol pilot and their comparison with standard limit.

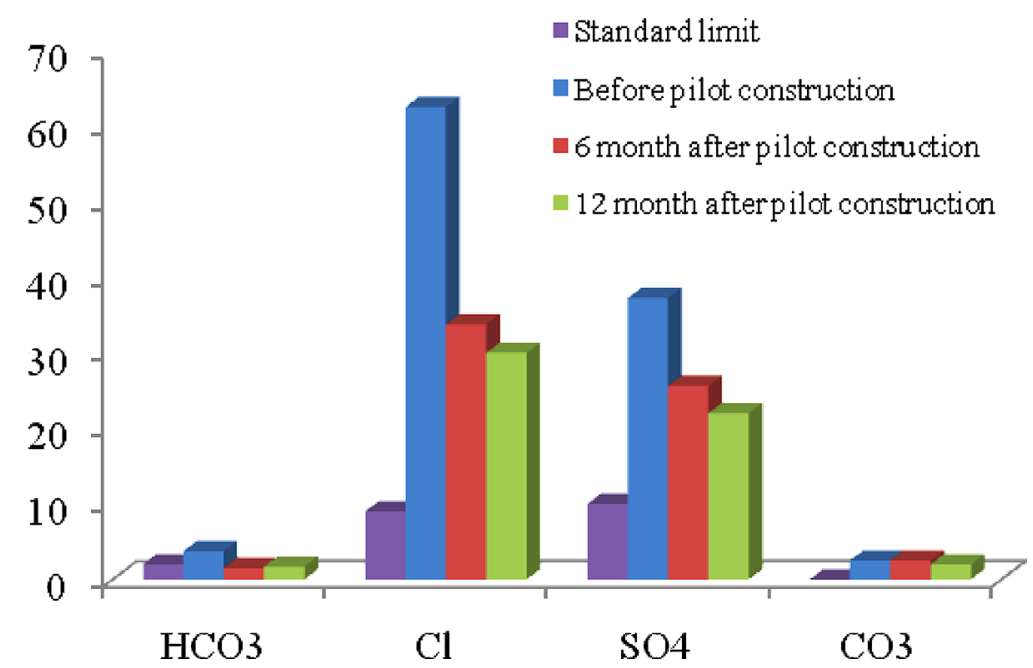

Figure 7: Chemical properties of the soil anions before and after the establishment of the Zabol pilot and their comparison with standard limits.

with the experimental data. The forecast results of the BP model for different conditions are listed in Table 2.

The comparative analysis of the predicted values and the BP neural network values showed that the maximum error was $19.23 \%$ whereas the minimum error was $1.17 \%$. The neural network had good identification ability and can grasp the essential relations among all impact factors in the system during the training, and the RI of all the input factors was obtained by calculation: $\mathrm{EC}_{\text {effluent }}$ was 40.48, $\mathrm{EC}_{\text {soil }}$ was 28.98, $\mathrm{SAR}_{\text {soil }}$ was $13.85, \mathrm{BOD}_{5}$ was 8.07, $\mathrm{ESP}_{\text {soil }}$ was 5.58, $\mathrm{SAR}_{\text {effluent }}$ was 3.04.

The RI indicated that the comparative influences of the six factors on the performance of the reactor were: $\mathrm{EC}_{\text {effluent }}>\mathrm{EC}_{\text {soil }}>\mathrm{SAR}_{\text {soil }}>\mathrm{BOD}_{5}>\mathrm{ESP}_{\text {soil }}>\mathrm{SAR}_{\text {effluent }} . \mathrm{EC}_{\text {effluent }}$ values were the most 


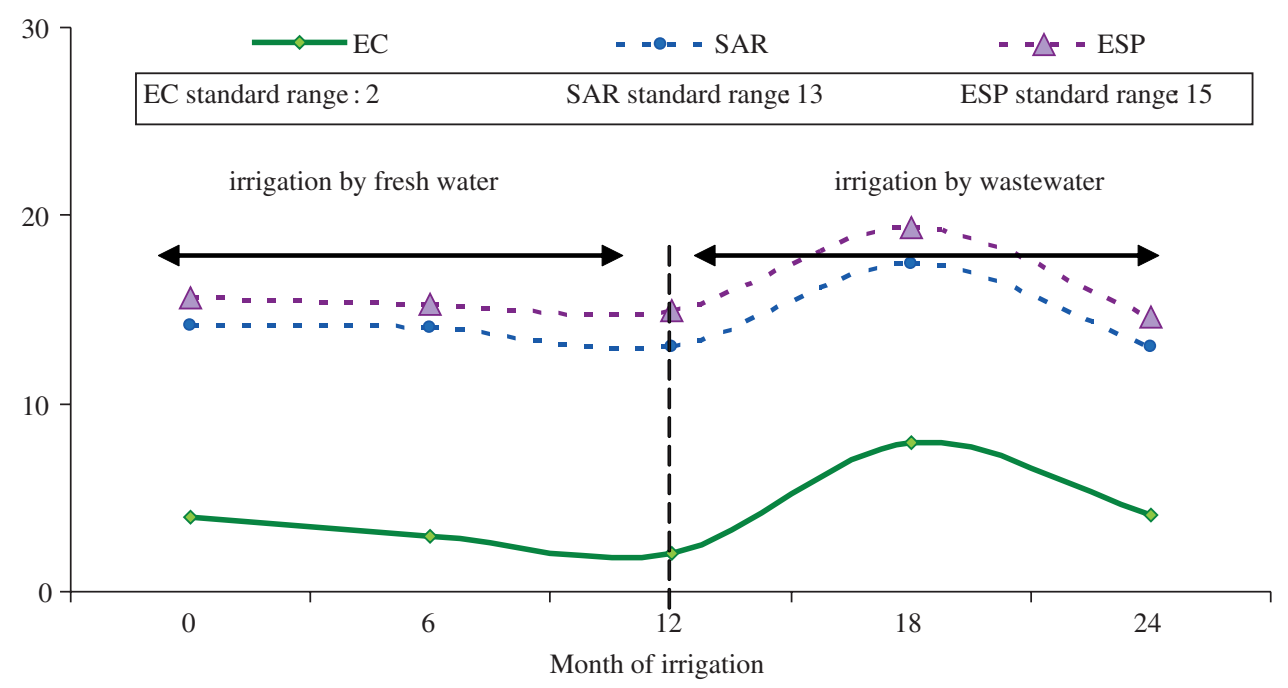

Figure 8: Quality of the soil for agriculture before and after the establishment of the Zabol pilot and their comparison with standard limits.

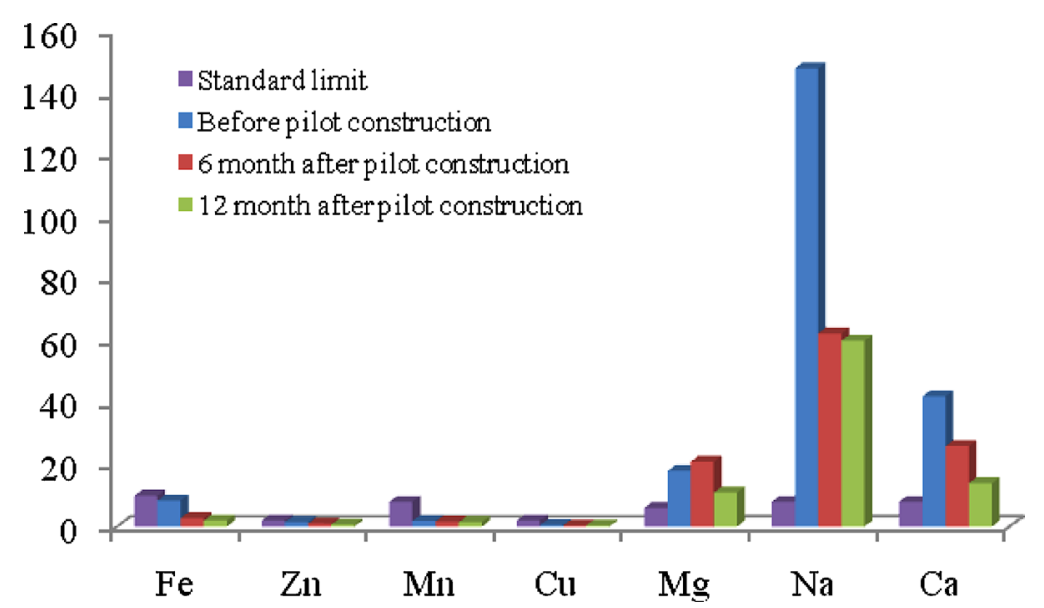

Figure 9: Chemical properties of the soil before and after the establishment of the Zahedan pilot and their comparison with standard limits.

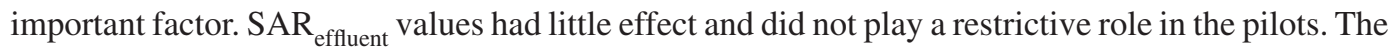
pilots were more sensitive to $\mathrm{SAR}_{\text {soil }}$ than $\mathrm{BOD}_{5}$.

\section{DISCUSSION}

The comparison between the chemical specifications of the fresh water supplied to homes and the treated wastewater shows that the alkalinity as well as the calcium and magnesium content of the treated wastewater is high.

Analysis of the results presented in Table 1 shows that some indicators are higher than the standard levels, e.g. SAR which is an important parameter in irrigation. If this parameter is higher than 18 , it 


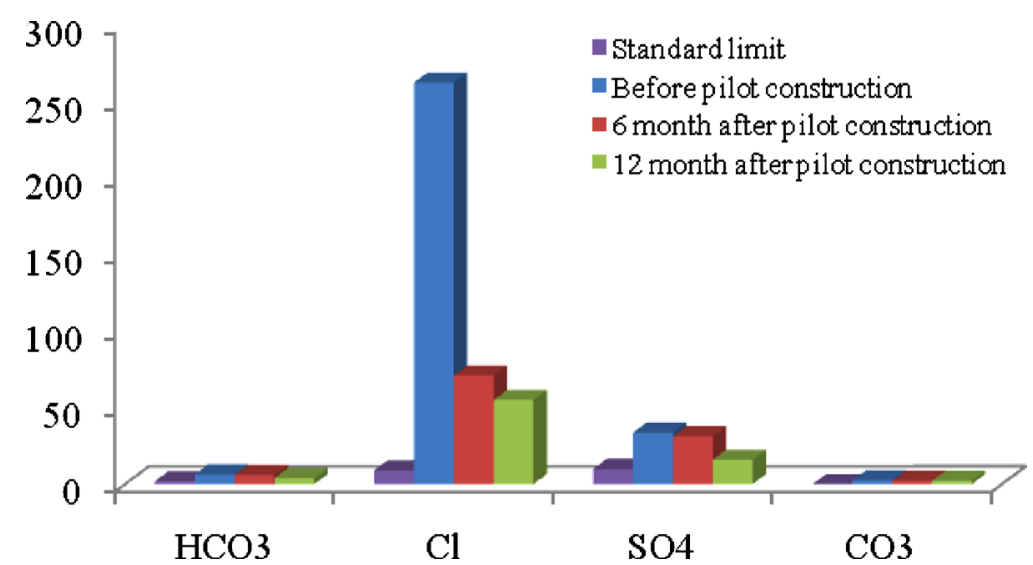

Figure 10: Chemical properties of the soil anions before and after the establishment of the Zahedan pilot and their comparison with standard limits.

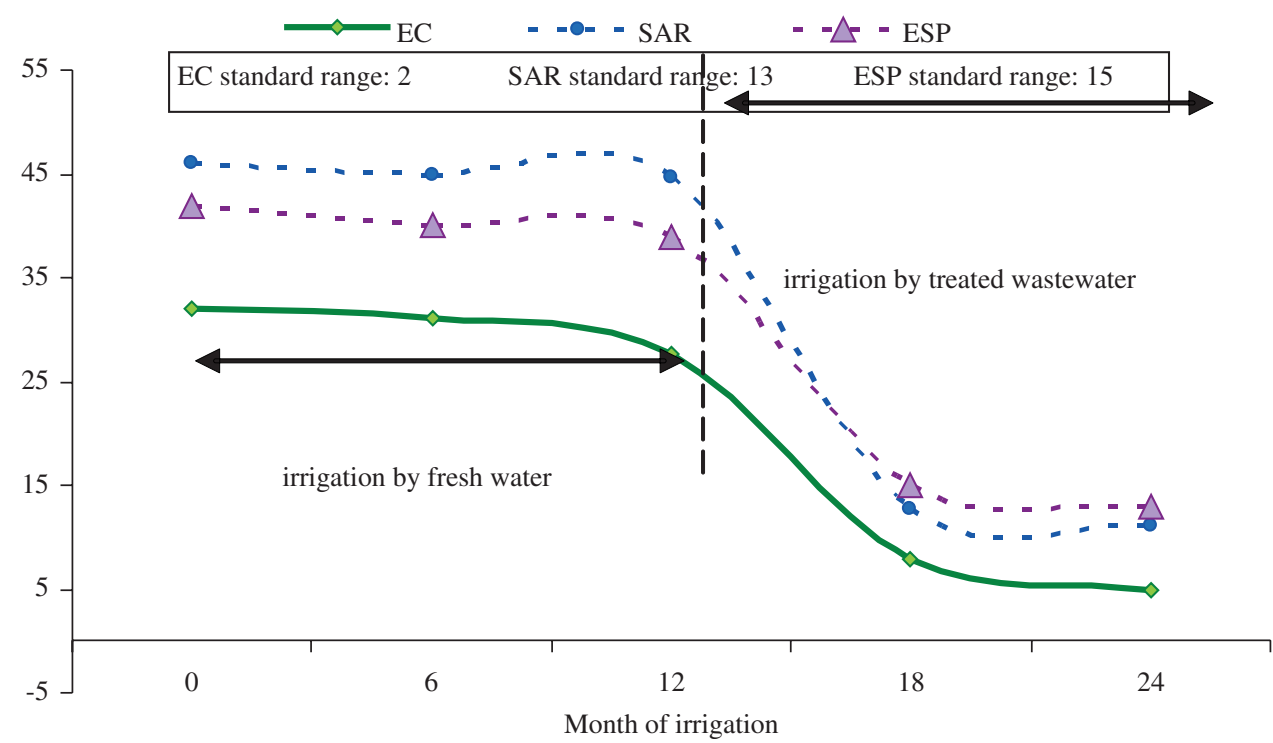

Figure 11: Quality of the soil for agriculture before and after the establishment of the Zahedan pilot and their comparison with standard limits.

will have an undesirable impact on the soil. In this test SAR and EC are in the maximum range of the standard levels. The concentration of $\mathrm{Na}^{+}$is more than expected. According to the standard levels, the rest of the measured parameters were acceptable for irrigation. Problems in the quality of the treated wastewater and the increase in the SAR, $\mathrm{Na} \%$, are not influenced by the efficiency of the WWTP. Adding calcium and magnesium to wastewater effluents can lead to a decrease in SAR and $\mathrm{Na} \%$ and increase in TDS and EC.

Irrigation water is the main source of addition of salts to soil, and its magnitude depends on the total water salinity, water composition, leaching requirements considered, soil type, drainage 
conditions, climate, management practices and the consumptive use of crops to be cultivated. In this study, although the values of some wastewater parameters were beyond the standard range, the results of the qualitative tests of the soil showed that the soil quality has improved after establishment of the pilots. Irrigation of pilots for 12 months with freshwater did not show a considerable change in the salinity soil quality in the pilots, but irrigation with treated wastewater had an appreciable effect on soil quality parameters. The values of soil EC, SAR and ESP prior to establishment of the Zahedan pilot were 27.6, 44.73 and 38.87, respectively. After irrigation of the pilots for a period of 6 months the values changed to 7.9, 12.7 and 15, respectively. In the 12 months after irrigation these values decreased to $81 \%, 75 \%$ and $66 \%$ for EC, SAR, and ESP, respectively. In the Zabol pilot, the values of soil EC, pH, SAR and ESP prior to establishment of the pilot were 7.98, $8.32,17.46$ and 19.39, respectively. After irrigation of the pilots for a period of 6 months these values changed to 4.04, 8.6, 13 and 14.6, respectively, which shows an improvement in the soil properties. After continuation of the irrigation for 12 months, these values decreased to $73 \%, 37 \%$ and $28 \%$ for EC, SAR and ESP, respectively. As shown in Fig. 8 the values of the quality parameters of soil increased between 12 and 18 months after irrigation because of variation in the effluent wastewater quality. These parameters approached the standard limit after 1 year of irrigation with treated wastewater. It can be said that these parameters improved after irrigation with RRW because of absorption of mineral substances by the soil from the treated wastewater. During the irrigation period, the $\mathrm{pH}$ value increased because of the existence of detergents in wastewater and the inability of the WWTP to treat these sufficiently. Similar studies in arid regions showed that SAR was reduced from 20.50 to 12.50 for a 20 -cm depth of RRW application. In this research, soil salinity and SAR of soil reached safe limits on irrigation with treated wastewater at a depth of $60 \mathrm{~cm}$ for a 3-month period.

\section{CONCLUSION}

This research investigated the feasibility of the reuse of treated wastewater from the existing WWTP facilities in the Iranian province of Sistan and Baluchestan for irrigation as a part of waste management in the form of a pilot study. An artificial neural network model which adopts a back propagation algorithm with momentum and adaptive learning rate was applied to compare the effect of each parameter on the performance of the Zahedan pilot.

The chemical properties of soil after irrigation with treated wastewater improved to the standard range in both the pilots. The growth and development of the planted species in the pilots was optimum and only in one case (pistachio) some problems were observed which were solved by changing the irrigation regime (decrease of irrigation).

Finally, the relative contributions of each factor to the performance were studied. The simulation results were in good agreement with the prototype experimental data and within the range of training data the latter results were as follows: $\mathrm{EC}_{\text {effluent }}>\mathrm{EC}_{\text {soil }}>\mathrm{SAR}_{\text {soil }}>\mathrm{BOD}_{5}>\mathrm{ESP}_{\text {soil }}>\mathrm{SAR}_{\text {effluent }}$. $\mathrm{EC}_{\text {effluent }}$ values were the most important factor. $\mathrm{SAR}_{\text {effluent }}$ values had little effect and did not a play restrictive role in the pilot. The pilots were more sensitive to $\mathrm{SAR}_{\text {soil }}$ than $\mathrm{BOD}_{5}$.

Based on these results, we suggest soil amendment by improvement of its quality using gypsum and sulphuric acid together with leaching. Also, some corrective actions should be taken to improve the wastewater quality at the outlet of the WWTPs either by improving the quality of the fresh water supplied to households or by upgrading the quality of the plants.

\section{REFERENCES}

[1] Gleick, P.H., Water Crisis: A Guide to the World's Freshwater Resources, Oxford University Press: Washington DC, USA, 1993. 
[2] UNCED, Protecting and Managing Freshwater. United Nations Conference on Environment and Development, Rio de Janeiro, 1992.

[3] Badalians Gholikandi, G., Wastewater Treatment Plant Design, Ketabiran - Ayeej Press: Tehran, Iran, 2009.

[4] Water Corporation Perth, Treated wastewater re-use, bulletin No. 2, http://www.watercorporation. com.au/publications/7/Treated_wastewater_reuse.pdf, 2004.

[5] Janosova, B., Miklankova, J., Hlavinek, P. \& Wintgens, T., Drivers for wastewater reuse: regional analysis in the Czech Republic. Desalination, 187, pp. 103-114, 2006.

[6] Harury, N., Agricultural reuse of wastewater: nation wide cost-benefit analysis, Journal of Agricultural Ecology and Environment, 66(2), pp. 113-119, 1997.

[7] Massoudinejad, M.R., Manshouri, M. \& Yazdanbakhsh, A.R., Study of the reuse of Zamyad factory wastewater treatment plant in irrigation, Iran Journal of Environmental Health Science and Engineering, 3(4), pp. 285-288, 2008.

[8] Pescod, M.D., Wastewater Treatment and Use in Agriculture, Food and Agricultural Organization (FAO), Irrigation and Drainage Paper, number 47, FAO: Rome, Italy, pp. 978-989, 1992.

[9] Taniyama, S. \& Adachi, O., Utilization of treated sewage water for irrigation in paddy field areas in Japan. Int. seventeenth congress on irrigation and drainage, International Commission on Irrigation and Drainage (ICID): Granada, Spain, (IG), pp. 45-53, 1999.

[10] Angelakis, A.N., Marecos do Monte, M.H.F., Bontoux, L. \& Asano, T., The status of wastewater reuse practice in the Mediterranean basin: need for guidelines. Water Research, 33(10), pp. 2201-2217, 1999. doi:10.1016/S0043-1354(98)00465-5

[11] Libro Blanco del Agua en España, Secretaria de Estado de Aguas y Costas junto a la Dirección General de Obras Hidráulicas y calidad de las Aguas del MMA, Ministerio de Medio Ambiente, 2000.

[12] Iglesias, R., Directrices para el avance de la regeneracióny reutilización de aguas en España. Jornadas sobre la integración del agua regenerada en la gestión de los recursos, Consorcio de la Costa Brava, 2005.

[13] Papadopoulos, I., Present and perspective use of wastewater for irrigation in the Mediterranean basin. 2nd Int. Symposium on Wastewater Reclamation and Reuse, eds. A.N. Angelakis, et al., pp. 735-746, 1995.

[14] Arabi, E 1., Rashed, M. \& Vermeulen, A., Environmental impacts of sewage water irrigation on groundwater, Int. Managing Environmental Changes Due to Irrigation and Drainage, Proceedings of Special Workshop, International Commission, 1996.

[15] Mahmoodian \& Syed Ali, Water from Water (A review of wastewater reuse in Iran). FAO/WHO conference in Jordan, 2001.

[16] Badalians Gholikandi, G. \& Lashkari, M., Treated Wastewater Reuse in Sistan ana Baluchestan Province, Research Report, Iran, 2007.

[17] Nasseri, S., Sadeghi, T., Vaezi, F. \& Naddafi, K., Evaluation of possible options for reuse of Ardebil wastewater treatment plant effluent. Iran Journal of Environment, Health Science Engineering, 3(4), pp. 285-288, 2006.

[18] Salehi Arjmand, H., Mehdian, MH., Kargari, A. \& Mehdia, M., Study the possibility of reusing Arak WWTP effluent in agriculture. Water and Environment, 65, pp. 41-46, 2006.

[19] Amjad, M., Salimi Saboor, S. \& Maghsoodloo, B., Study the opportunities of reusing municipal wastewater of the city of Yazd. 9th National Congress on Environmental Health, Isfahan, 2006.

[20] Massoudinejad, M.R., Evaluation of Maharlou Lake to Salt Pollution and Heavy Metals Because of Municipal Wastewater Discharged to the Khosk River, research plan, Research Department of Shiraz Medical Sciences University, pp. 255-270, 1994. 
[21] Laberge, C., Laberge, C., Cluis, D. \& Mercier, G., Metal bio-leaching prediction in continues proceedings of municipal sewage with Thiobacillus thiooxidans using neural networks. Water Research, 34(4), pp. 1145-1156, 2000. doi:10.1016/S0043-1354(99)00246-8

[22] Department-General of Agriculture of Sistan and Baluchestan Province, Report on Agricultural Insight of the Province, 1997.

[23] Khosravi, M., Adverse bioclimatic effects of the natural environment on Sistan plain, Geographic Researches Quarterly, Issue No. 13, 1989.

[24] Office of Regional Planning, Management and Planning Organization Study of Development of East of the Country, Vol. II, 1988.

[25] International Conference on Sustainable Irrigation 2008, WIT Transactions on Ecology and Environment (ISSN 1743-3541), Vol. 112, WIT Press: Southampton, UK, www.witpress.com.

[26] Tian, Q.-C., Research on leaning algorithm of BP network Ba Sed on the Metropolitics Critirian control theory and application. Ecological Modelling, 5, pp. 15-17, 2005.

[27] Gevrey, M., Dimopoulos, I. \& Lek, S., Review and comparison of methods to study the contribution of variables in artificial neural network models. Ecological Modelling, 160, pp. 249-264, 2003. doi:10.1016/S0304-3800(02)00257-0 